\title{
Evaluation of Cooking Oil as Processing Addtive for Natural Rubber
}

\author{
Y. M. SYAMIN ${ }^{1}$, S. AZEMI ${ }^{2 *}$ AND K. DZARAINI ${ }^{3}$
}

\begin{abstract}
It was reported recently that high amount of aromatic ring or number of polycyclic aromatic hydrocarbon compounds found in aromatic oil are carcinogenic. This paper discusses the work to evaluate the Malaysian cooking oil as an alternative option to be used as process oil since cooking oil is safe to use and non-toxic. The performance of cooking oil is compared against aromatic and paraffinic oils. The results showed that rubber compounds containing cooking oil produced almost similar cure characteristics as those produced by aromatic and paraffinic oils indicating that it did not interfere with the vulcanization reaction. The physical properties of the vulcanizates containing cooking oil were almost similar to those of vulcanizates containing aromatic and paraffinic oils, except the rebound resilience. The vulcanizates containing cooking oil gave higher resilience than vulcanizates containing aromatic and paraffinic oils. High resilience is one of the desired features for a low rolling resistance tyre. Cooking oil provided this extra advantage.
\end{abstract}

Key words: Mooney viscosity; cure time; tensile strength; hardness and resilience

Aromatic oil has been used as rubber processing additive for centuries. The oil aids the mixing process such as to ease the incorporation of filler into the rubber and facilitates dispersion of fillers. In extrusion and calendering processes, the oil reduces heat generation and improves flow. Aromatic oil is known for high levels of aromatics (>65\% wt, CA > 35\%) (BP 1982), multiple-ring compounds, impart odour, low oxidation stability and high reactivity. The main characteristic of aromatic oil is associated with its excellent compatibility with most of the rubber. Aromatic oil also gives softening characteristic for improving the workability of rubber composition (Hasimoto 2000). However, recently it was reported that carcinogenic chemicals found in the petroleum process oils can be dangerous to human health (Swedish Ntional Chemical Inspectorate 2003; Dasgupta et al. 2009). The high aromatic oil contains large quantities of aromatic and polyaromatic hydrocarbons (PAHs), up to 10-30 percent (Swedish Ntional Chemical Inspectorate 2003; Dasgupta et al. 2009). Several of the PAHs contained in aromatic oils are classified as carcinogenic. A carcinogen is any substance, radionuclide or radiation that is an agent directly involves in the promotion of cancer or in the increase of its propagation (Wikipedia n.d.). This paper discusses some of the preliminary work to evaluate Malaysian cooking oil (palm oil with a brand name Minyak Masak Cap Pisau by Loon) as an alternative process oil for rubber mixing. Cooking oil is harmless

\footnotetext{
${ }^{1}$ Proreka (M) Sdn Bhd, No. 17 Jalan Industri PBP 3, Taman Industri Pusat Bandar Puchong, 47000 Puchong, Selangor

${ }^{2}$ Iprus Sdn Bhd, C-3-1 Block C, Pacific Place Commercial Centre, Jalan PJU 1A/4, 47301 Ara Damansara, Selangor

${ }^{3}$ Department of Polymer Technology, Faculty of Applied Sciences, Universiti Teknologi MARA, 40450 Shah Alam, Selangor

*Corresponding author (e-mail: azemi.sam@gmail.com)
} 
and contains several saturated and unsaturated fats in the forms of lauric $(0.1 \%$, saturated), myristic $(0.1 \%$, saturated), palmitic $(44 \%$, saturated), stearic (5\%, saturated), and oleic (39\%, monounsaturated). Most of the current commercial processing additives are based on fatty acid soaps.

\section{EXPERIMENTAL}

\section{Mix Formulations}

Table 1 shows the mix formulations where the variables are the type and quantity of process oil used. Mixing was done in a laboratory Banbury mixer. The total mixing time in the mixer was five minutes. The mix was finalized by mixing with the curatives on a two-roll mill immediately after the mix was discharged.

\section{Cooking Oil}

Palm oil with a brand name Minyak Masak Cap Pisau by Loon. The density of cooking oil is $0.89 \mathrm{~g} / \mathrm{cm}^{3}$, the fat content of cooking oil is $90 \mathrm{~g}$ at every $100 \mathrm{ml}(9 \%$ fats per $100 \mathrm{ml})$.
The viscosity of cooking oil at $28^{\circ} \mathrm{C}$ is $6.66 \times$ $10^{-3}$ Pa.sec.

\section{Aromatic Oil (Tudalen 65)}

The specific gravity of the aromatic oil by the ASTM Test Method (D1250) is around 0.95 to $1.00 \mathrm{~g} / \mathrm{cm} 3$, while the molecular weight by $\operatorname{ASTM}(D 2502)$ is around $300-700$ and the aromatic content ASTM (D2007) in terms of percentage $(\%)$ is around $65-85$. In this work, the aromatic oil was Tudalen 65 and the amount varied from $5 \mathrm{pphr}$ to $20 \mathrm{pphr}$.

\section{Paraffinic Oil}

Paraffinic oil is oil distinguished by a molecular structure composed of long chains of hydrocarbons linked in a long linear series similar to a chain. It has high levels of isoparaffinic molecules. Paraffinic oil is more oxidative stability compared to aromatic and naphthenic oil and lower in odour. The level of monoaromatics is similar to those of the aromatic oil, but much lower levels of multiring aromatic process oil. The paraffinic oil used here is Nytex 840 . The amount varied from 5 pphr to $20 \mathrm{pphr}$.

Table 1. Formulations.

\begin{tabular}{c|ccccc}
\hline Mix number & 1 & 2 & 3 & 4 & 5 \\
\hline NR (SMR L) & 100 & 100 & 100 & 100 & 100 \\
Zinc Oxide & 5 & 5 & 5 & 5 & 5 \\
Stearic Acid & 2 & 2 & 2 & 2 & 2 \\
Santoflex 13 & 3 & 3 & 3 & 3 & 3 \\
HAF (N330) & 50 & 50 & 50 & 50 & 50 \\
$*$ Process Oil & - & 5 & 10 & 15 & 20 \\
Sulphur & 2.5 & 2.5 & 2.5 & 2.5 & 2.5 \\
$* *$ CBS & 0.75 & 0.75 & 0.75 & 0.75 & 0.75 \\
\hline
\end{tabular}

*Process oil - three different types of process oil are being investigated. 


\section{Mooney Viscosity}

Mooney viscosity measurement was done by using Mooney viscometer at $100^{\circ} \mathrm{C}$ in accord with $I S O / R 289$. The results were expressed as ML $(1+4)$, in torque units, indicating a preheat time of 1 minute and a reading time of 4 minutes at test temperature $100^{\circ} \mathrm{C}$.

\section{Cure Characteristics}

The cure characteristics such as the scorch time $t_{2}$ and optimum cure time $t_{95}$ were determined from the oscillating disc cure meter in accord with ISO 3417.

\section{Tensile, Hardness, and Resilience Test}

Tensile test was done in accord with ISO 37. Hardness test was done in accord with ISO 48 and resilience test was done in accord with $B S$ 903.

\section{RESULTS AND DISCUSSIONS}

\section{Physical Tests on Unvulcanized Rubber Compound}

Mooney viscosity. In the absence of process oil, the Mooney viscosity of the rubber compound was relatively high about 68 Mooney units (MU). In the presence of process oil, the Mooney viscosity decreased progressively as the quantity of oil increased as shown by the histogram in Figure 1. This behaviour is attributed to the effect of diluents from the oil softening associated with the swelling of rubber and enhancement of molecular flow associated with the lubrication. All the three process oils produced comparable Mooney viscosity at each oil loading.

Cure Characteristics. The effect of the type and quantity of process oil on scorch time $\mathrm{t}_{2}$ and cure time $\mathrm{t}_{95}$ is shown in Figures 2 and 3 , respectively. The aromatic oil gave slightly better processing safety i.e. longer scorch time than the other two types of oil. In the case of optimum cure time $t_{95}$, there was not much difference among these three process oils. The paraffinic oil contributed slightly higher $t_{95}$ than the other two oils at 15 and $20 \mathrm{pphr}$ oil loading. The results showed that cooking oil produced almost similar cure characteristics of the rubber compound as that produced by aromatic process oil.

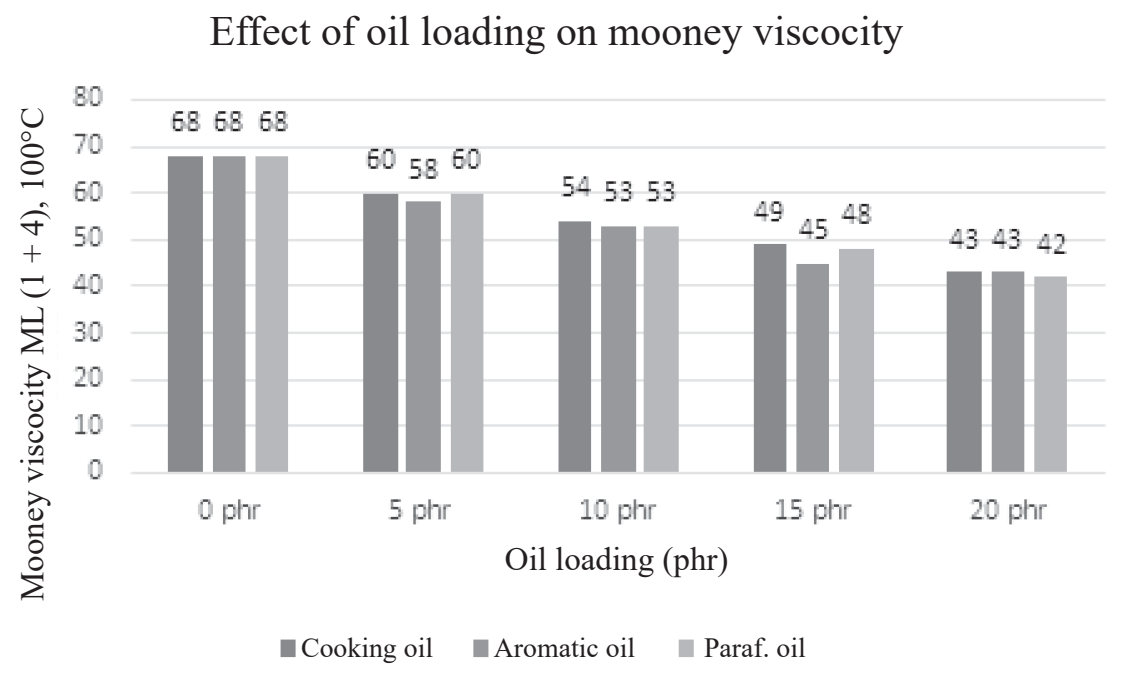

Figure 1. Influence of types of oil and quantity of oil on Mooney viscosity of rubber compound. 


\section{Effect of oil loading on scorch time at $130^{\circ} \mathrm{C}$}

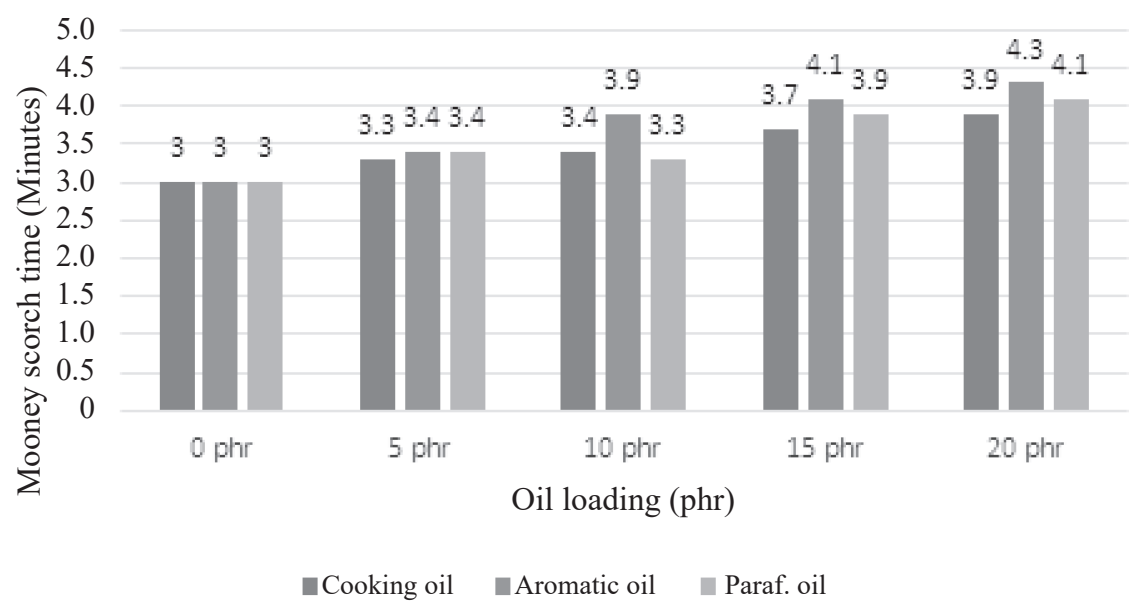

Figure 2. Effect of type and quantity of oil on scorch time $t_{2}$ of rubber compound.

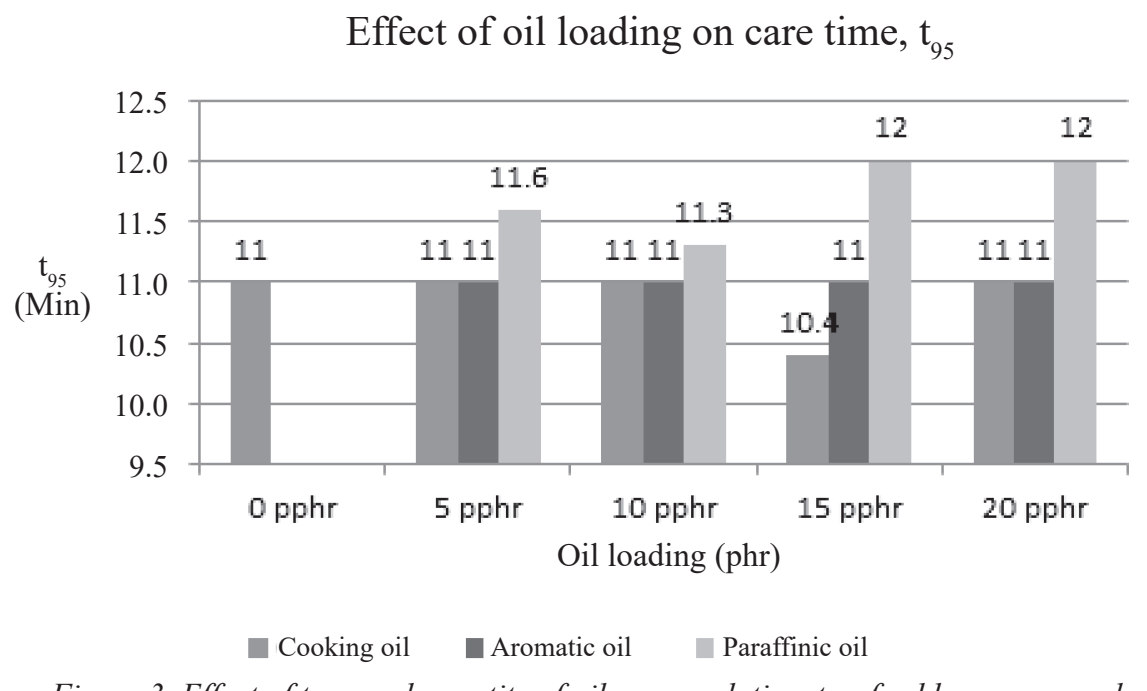

Mechanical and Physical Tests for Hardness and Tensile Strength of Vulcanized Rubber

Hardness. Hardness is defined as the resistance to surface indentation as measured under specified conditions. It is a non-destructive test that measures the reversible deformation when an indenting force is applied on the rubber surface at a specified time. Hardness test is widely used in quality control because hardness is sensitive to filler loading and also the state of cure.

The histogram in Figure 4 shows that the hardness decreases steadily as the quantity of oil in the vulcanized rubber increases. It is well established that the main function of the oil is to facilitate during processing (such as mixing, calendering and extrusion) by lubricating and 


\section{Effect of oil loading on hardness}

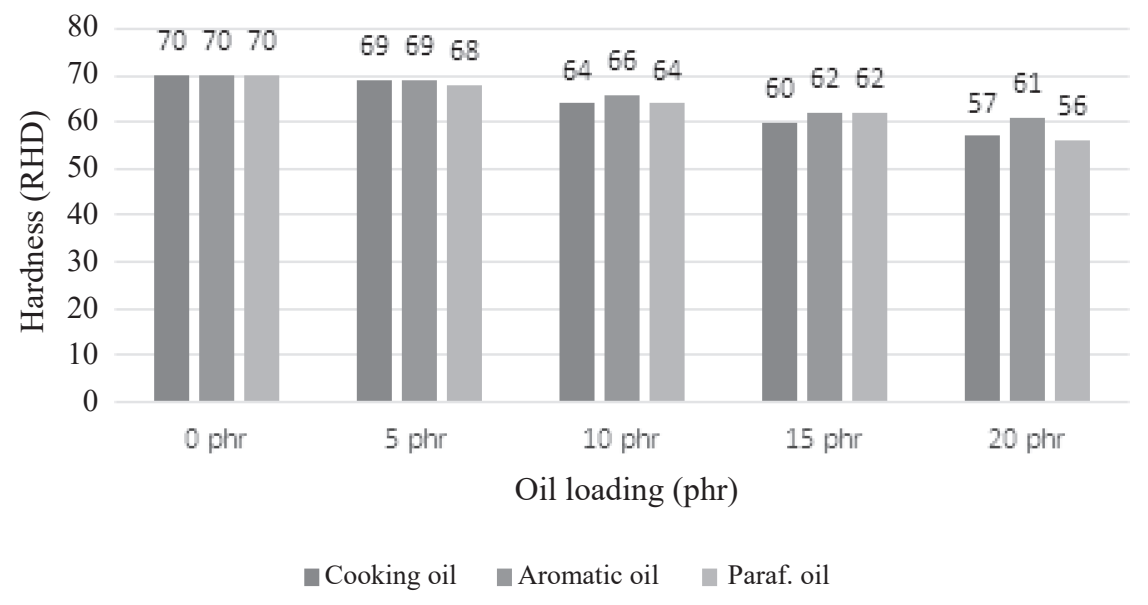

Figure 4. Effect of type and quantity of process oil on hardness of vulcanized rubber.

softening to ease rubber flow. The hardness decreased with increasing quantity of oil because the rubber became softer at higher oil loading than at low oil loading since the plasticizing and swelling effects were more effective at higher oil loading than at low oil loading. This softening was consistent with the results shown in Figure 1 where the Mooney viscosity decreased with increasing quantity of oil. Thus, this indicates that, apart from filler and crosslink concentration, the quantity of oil also affected the hardness markedly. The type of oil did not cause much difference in hardness especially at $5 \mathrm{pphr}$ of oil. At $20 \mathrm{pphr}$ of oil, the aromatic oil contributed slightly higher hardness than paraffinic and cooking oils.

Tensile strength. The histogram in Figure 5 shows that the tensile strength of vulcanized black-filled NR is not markedly affected by

\section{Effect of oil loading on tensile strength}

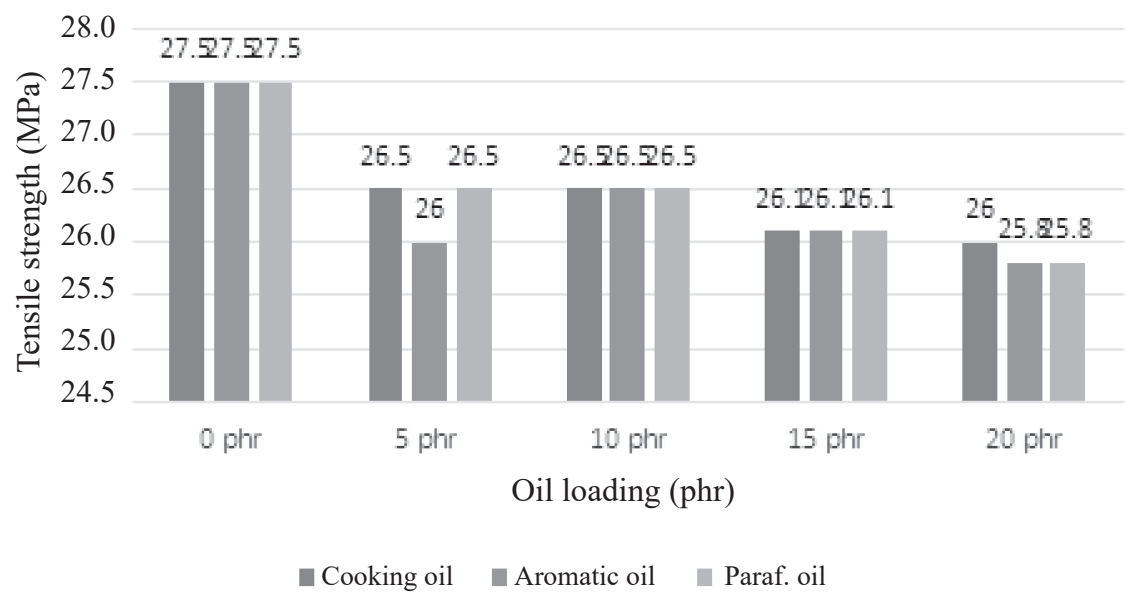

Figure 5. Effect of oil on tensile strength (unaged). 
the type of oil. There is a marginal decrease of tensile strength as the quantity of oil increases. This decrease is associated with the dilution effect (Azemi 2012; Azemi 2014). Apart from the dilution effect, tensile strength also decreased when the molecular interaction between rubber chains was reduced because the rubber molecules were further apart since the rubber was in the swollen state. The decrease in the molecular interaction also responsible for the increase in elongation at break as shown in Figure 6. Here, the cooking oil gave slightly higher elongation at break than aromatic and paraffinic oil probably because the former contributed higher lubricating effect since the former had lower viscosity than the latter.

\section{Physical Tests for Tensile Strength After Heat Aging}

Tensile Strength. However, the type of oil affects the tensile strength after accelerated heat aging. Figures 7, 8 and 9 showed the plot of tensile strength after accelerated heat aging for 7 days at $70^{\circ} \mathrm{C}, 14$ days at $70^{\circ} \mathrm{C}$ and 1 day at $100^{\circ} \mathrm{C}$, respectively. The results showed that the tensile strength was higher in samples with oils than the control sample (without process oil). Azemi (2012 \& 2014) attributed this behaviour to the phenomenon known as supercoiled network. The presence of oil in the rubber compound causes the rubber molecules to be pushed apart as if they are extended (as a consequence of swelling). During vulcanization, crosslinks are formed between these extended rubber molecules. When the diluent (oil or solvent) is then removed by extraction (or by evaporation) (Azemi 2012) the network collapses (disappearance of swelling) and forms supercoiled network. The aromatic and the paraffinic oils give higher tensile strength than that of vulcanizates containing cooking oil. The longer the aging period and the higher is the temperature of heat aging the lower is the tensile strength.

Resilience. Figure 10 showed an impressive result where cooking oil gave higher resilience than the other two process oils especially at oil loading more than $10 \mathrm{pphr}$. There was a general trend where the rebound resilience decreased progressively with increased oil loading.

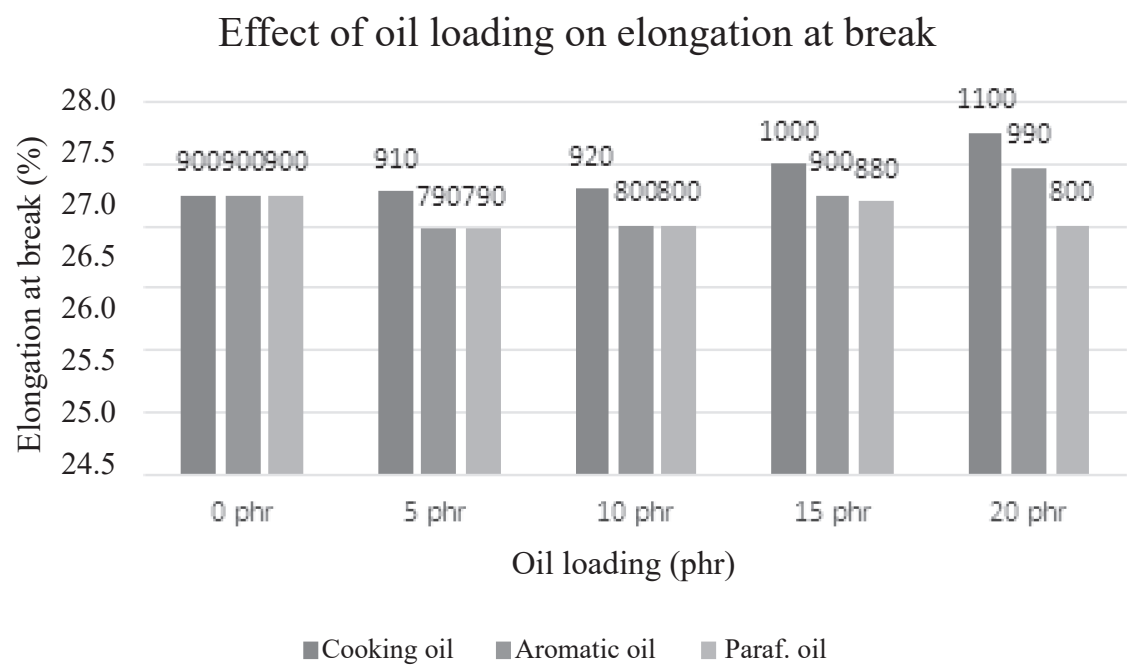

Figure 6. Effect of oil on elongation at break (unaged). 
Effect of oil loading in tensile strenght after heat aging at $7 \mathrm{~d} / 70^{\circ} \mathrm{C}$

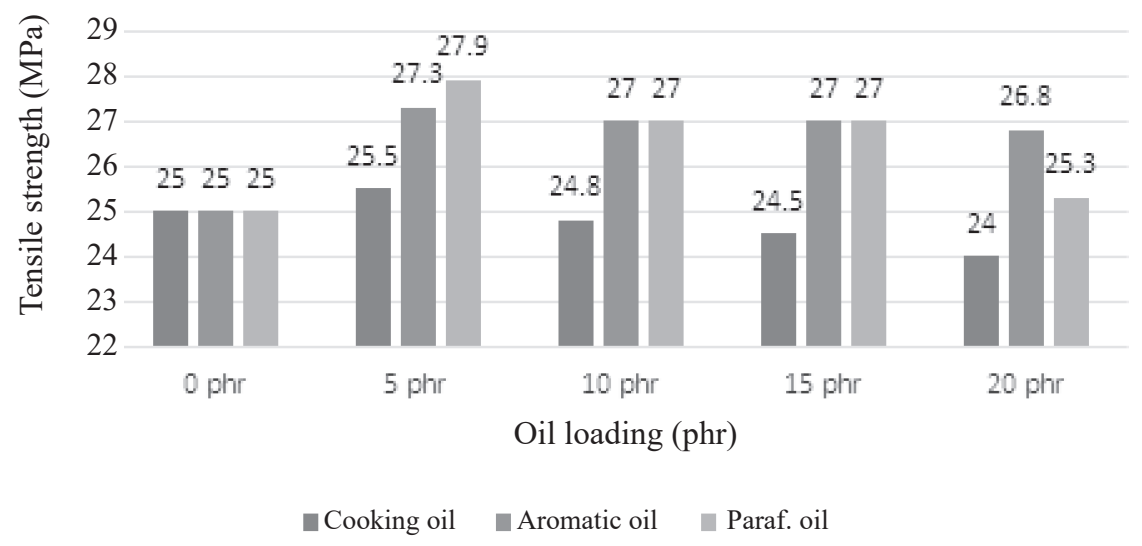

Figure 7. Influence of types of oil on tensile strength after accelerated heat aging at $70^{\circ} \mathrm{C}$ for 7 days.

Effect of oil loading in tensile strenght after heat aging at $14 \mathrm{~d} / 70^{\circ} \mathrm{C}$

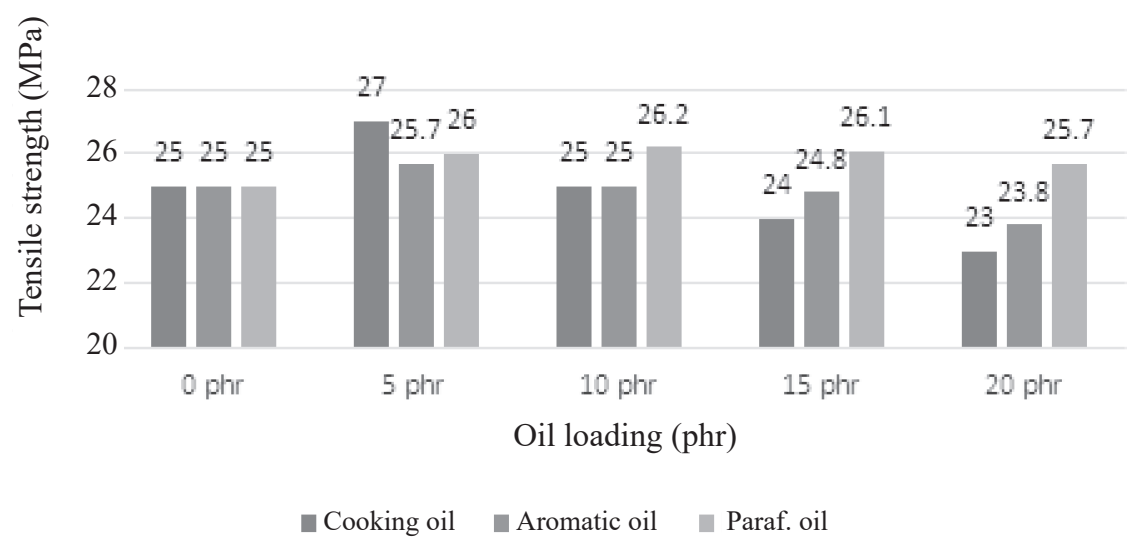

Figure 8. Influence of types of oil on tensile strength after accelerated heat aging at $70^{\circ} \mathrm{C}$ for 14 days. 


\section{Effect of oil loading in tensile strenght after heat aging at $1 \mathrm{~d} / 100^{\circ} \mathrm{C}$}

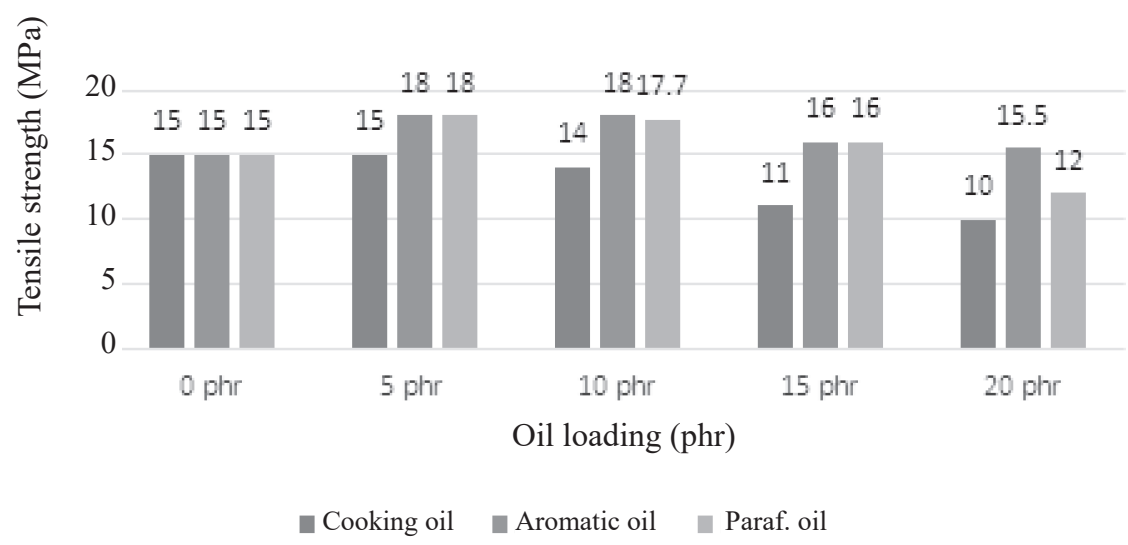

Figure 9. Influence of types of oil on tensile strength after accelerated heat aging at $100^{\circ} \mathrm{C}$ for 1 day.

The rebound resilience was greatly influenced by the glass-transition temperature $T_{\mathrm{g}}$, crosslink concentration and filler loading. Table 2 shows the $T_{\mathrm{g}}$ of the vulcanized rubber reproduced from the work published by Azemi (2012). The aromatic oil gives higher $T_{\mathrm{g}}$ by $2^{\circ} \mathrm{C}$ to $3^{\circ} \mathrm{C}$ at 5 and $10 \mathrm{pphr}$ of oil, and a difference of about $8^{\circ} \mathrm{C}$ at oil loading higher than $25 \mathrm{pphr}$. The results indicate that process oil is not a true plasticizer, but a softener or lubricant since the reduction in $T_{\mathrm{g}}$ is not substantial. The fact that the resilience decreases with increase oil content suggests that the oil acts as a damper.
Indeed the high quantity of aromatic oil is incorporated into highly filled NR to give high damping for compounding of natural rubber for seismic rubber bearings. The cooking oil exhibited higher resilience than aromatic and paraffinic oils because the viscosity of the former was lower than the latter. The low damping characteristic of cooking oil (high resilience) was one of the desired features for a low rolling resistance tyre. Cooking oil provided this extra advantage.

Table 2. Glass transition temperature $T_{\mathrm{g}}$ of unfilled NR vulcanizate.

\begin{tabular}{ll|ccccccc}
\hline \multirow{2}{*}{ Oil (pphr) } & $\begin{array}{l}\text { Raw SMR L } \\
\text { Standard }\end{array}$ & 0 & 5 & 10 & 25 & 35 & 40 \\
& & & & & & & \\
\hline$T_{\mathrm{g}}{ }^{\mathrm{O}} \mathrm{C}$ & (Aromatic) & -72 & -69.3 & -68.9 & -69.3 & -69.3 & -69.1 & -69.6 \\
$T_{\mathrm{g}}{ }^{\mathrm{O}} \mathrm{C}$ & (Paraffinic) & -72 & -69.3 & -71.3 & -72.3 & -77.3 & -78.0 & -78.6 \\
\hline
\end{tabular}

(Note: $T_{\mathrm{g}}$ was determined using DSC heating from $-100^{\circ} \mathrm{C}$ to $0^{\circ} \mathrm{C}$ at $20^{\circ} \mathrm{C}$ per minute. Calibration was by cyclohexane. Also standard raw NR $T_{\mathrm{g}} \mathrm{S}$ were measured before and after the sample series. The sample $T_{\mathrm{g}} \mathrm{s}$ were then corrected). 


\section{CONCLUSION}

Cooking oil was suitable to be used as process oil for rubber compounds. It showed almost similar behaviour with the commonly used process oils such as aromatic and paraffinic types. Cooking oil possessed further advantages of having low damping characteristics and being non-toxic.

\section{AKNOWLEDGEMENT}

The authors would like to express their thanks to the Dean of the Faculty of Applied Sciences for the consent to present this work at the International Polymer Technology Conference and Exhibition 2013.

\section{REFERENCES}

BP 1982, An Introduction to Process Oils, BP, MP584/82.

Hashimoto, T 2000, High aromatic oil and rubber composition and oil extended synthetic rubber using the same, U.S. Patent 6103808.

Swedish National Chemical Inspectorate (KemI) 2003, HA oils in automotive tres: prospect of national ban, Report no. 5/03.

S. Dasgupta, S, Agrawal, SL \& Bandyopadhyay, S et al. 2009, 'Eco-friendly processing oils: a new tool to achieve the improved mileage in tyre tread', Polymeer Testing, vol. 28, no. $3,251-263$.

Wikipedia (nd), 'Carcinogen - Wikipedia, the free encyclopaedia, viewed 20 October 2009, <http://en.wikipedia.org/wiki/ Carcinogen $>$.

Azemi, S 2012, 'Effect of acetone extraction on elastic constants and mechanical strengths', J. nat. Rubb. Res., vol. 15, no. 1, pp. 1-18.

Azemi, S 2014, ' Theory and mechanism of reinforcement in natural rubber', in Natural Rubber Materials, vol. 2, Composites and Nanocomposites chap 3, ed S Thomas et al., Royal Society of Chemistry, UK. 